\title{
Versatility of the Free Anterolateral Thigh Flap in the Reconstruction of Large Defects of the Weight- Bearing Foot: A Single-Center Experience with 20 Consecutive Cases
}

\author{
Marco Pappalardo, MD $\quad$ Seng-Feng Jeng, MD, FACS ${ }^{1} \quad$ Parviz L. Sadigh, MB ChB ${ }^{1}$ Hsiang-Shun Shih, MD ${ }^{1}$ \\ ${ }^{1}$ Department of Plastic Surgery, E-Da Hospital, I-Shou University, \\ Kaohsiung City, Taiwan \\ Address for correspondence Hsiang-Shun Shih, MD, Department of \\ Plastic Surgery, E-Da Hospital, No. 1, Yi-Da Road, Jiao-Su Village, \\ Yan-Chao District, Kaohsiung City 824, Taiwan \\ J Reconstr Microsurg 2016;32:562-570. \\ (e-mail: shih0825@ms37.hinet.net).
}

\begin{abstract}
Background Reconstruction of the weight-bearing surface of the foot represents a challenging task. With very little scope to borrow glabrous tissue from adjacent areas means that achieving a "like for like" reconstruction is rarely possible. In this setting, alternative approaches need to be considered. In this article we present our experience with various differing designs of the anterolateral thigh flap (ALT) in the reconstruction of 20 large defects of the weight-bearing sole.

Methods Twenty patients with complex soft tissue defects of the weight-bearing sole underwent reconstruction over a 5-year period. Five cases were complicated by osteomyelitis resulting in significant calcaneal defects. The follow-up period ranged from 8 to 48 months and outcomes were assessed by two-point discrimination and protective sensation, observation of gait, and the ability of the patient to return to wearing normal footwear.

Results All flaps survived with the exception of two partial skin necrosis. Sensory nerve coaptation was performed in 12/20 cases. One patient underwent second-stage total

\section{Keywords}

- weight-bearing sole reconstruction

- calcaneal reconstruction

- anterolateral thigh perforator flap calcaneal reconstruction with a fibula osteocutaneous flap. Five large defects were reconstructed with the split skin paddle technique to allow for direct donor-site closure. No evidence of postoperative ulceration was noted in any of the patients over the followup period and all were satisfied regarding the functional and aesthetic results achieved. Conclusion Complex defects of the weight-bearing sole can be successfully reconstructed using the free ALT flap resulting in very favorable functional outcomes. Even when calcaneal osteomyelitis has set in, excellent outcomes can be achieved.
\end{abstract}

Successful reconstruction of the weight-bearing surface of the foot represents a reconstructive challenge to the plastic surgeon, owing to the unique anatomical and functional characteristics of this region. The plantar glabrous skin, the subcutaneous tissue, rich with thick septae, and the calcaneus all play key roles in standing and normal gait. Restoration of weight-bearing function, therefore, requires careful and considered reconstruction of these anatomic components. ${ }^{1}$ In

received

January 8, 2016

accepted after revision

April 3, 2016

published online

June 21, 2016
1986, Hidalgo and Shaw classified foot injuries into three types based on the degree of soft tissue and bony involvement. ${ }^{2}$ Type I corresponds to small soft tissue defects, type II represents large soft tissue defects without bony involvement, and type III represents large soft tissue defects with bony involvement. Although many type I defects can be managed with local flaps from the plantar region ${ }^{3-5}$ or indeed regional flaps ${ }^{6,7}$; for the larger and more complex types II and
Copyright $\odot 2016$ by Thieme Medical Publishers, Inc., 333 Seventh Avenue, New York, NY 10001, USA. Tel: +1(212) 584-4662.
DOI http://dx.doi.org/ 10.1055/s-0036-1584204. ISSN 0743-684X. 
III defects, free tissue transfer invariably represents the best reconstructive option. ${ }^{8}$ Currently most authors advocate two main reconstructive strategies for large soft tissue defects of the sole, namely skin-grafted free muscle flaps or free fasciocutaneous flaps. ${ }^{8-14}$ Indeed, perforator flaps also represent an attractive reconstructive option. ${ }^{15}$

Since its description by Song et al in $1984,{ }^{16}$ the anterolateral thigh flap (ALT) has become a popular choice with many reconstructive surgeons due to its long pedicle length, sizable vessels for microanastomosis, and good donor-site profile. Regarding reconstruction of complex plantar defects, perhaps the main advantage of the ALT is the variation in its design that can be achieved secondary to its versatile yet variable vascular anatomy. Indeed, the ALT has recently become our fasciocutaneous perforator flap of choice when tackling these challenging cases. In addition, a large cutaneous surface area can be harvested from a single donor site, it can be harvested as a sensate flap and its thickness can be reliably thinned at the same sitting. With complex defects of the foot (type III) with associated calcaneal osteomyelitis, it can also be harvested with a cuff of vastus lateralis to obliterate dead space. Moreover, the donor-site morbidity can be minimized by harvesting a split skin paddle based on two or more sizable perforators, thus allowing for direct closure of the donor site at the same time as achieving a bespoke three-dimensional reconstruction.

\section{Methods}

Between January 2008 and September 2013, 20 patients (14 males, 6 females) were treated for large defects of the weight-bearing foot with free ALT flaps. Age ranged from 17 to 75 years old with a mean of 48.5 years. The defects were secondary to trauma in 15 cases, malignant melanoma in 2 cases, diabetic ulceration in 2 cases, and limb ischemia in 1 case. Four traumatic defects were initially treated by skin grafting in the first instance that resulted in recurrent ulceration and contractures. The size of the defects ranged from 80 to $300 \mathrm{~cm}^{2}$ with a mean size of $180 \mathrm{~cm}^{2}$.

According to the Hidalgo and Shaw classification, ${ }^{2}$ we defined 15 defects as type II and 5 defects as type III. Six patients had associated fractures whereas five presented calcaneal osteomyelitis with one of these progressing to total calcaneal loss. Defects were analyzed based on site, size, condition of the underlying bone, presence of infection, and patient comorbidities. These are presented in -Table 1.

We raised the ALT flaps using the manner described in previous reports. ${ }^{17,18}$ When a sensate flap was required, care was taken to include branches of the lateral femoral cutaneous nerve ( $\mathrm{LFCN}$ ) found in the lateral aspect of the proximal portion of the skin paddle. Antibiotic beads (Zimmer Bone Cement [Heraeus Medical, Manufactured by Heraeus Kulzer $\mathrm{GmbH}$, Wehrheim, Germany] with vancomycin $2 \mathrm{~g}+$ gentamicin $320 \mathrm{mg}$ ) were deployed for patients with calcaneal osteomyelitis after bony debridement had been performed. To ensure direct donor-site closure, the width of the skin paddle was confined to no more than $16 \%$ of the thigh circumference. ${ }^{19}$ For defects wider than this, we recommend splitting the skin paddle, based on at least two sizable perforators, as this not only ensures direct donor-site closure but also a three-dimensional inset at the recipient site. Indeed, by adopting this policy, one can achieve a bespoke subunit-like reconstruction when dealing with large defects involving the heel and sole, while minimizing the impact on the donor site and avoiding the need for a skin graft. This modification would be planned preoperatively by mapping at least two perforators of the lateral circumflex femoral system with handheld Doppler. The flap would then be raised as a single skin paddle before being split into two separate flaps nourished by the same source vessel. These skin paddles could then be arranged to provide a three-dimensional reconstruction. The skin paddle appointed to the non-weight-bearing zone will be primarily thinned to improve contour and the paddle appointed to the weight-bearing area will overlap a deepithelialized portion of the thinned skin flap to provide additional cushioning to the heel.

Patients with no associated fracture were permitted to partially weight-bear with crutches after 3 to 4 weeks. Those with associated calcaneal osteomyelitis were permitted gradual weight bearing on the flap at 6 to 18 weeks postoperatively, depending on the severity of the calcaneal defect. During the follow-up period, functional and sensory evaluations of outcomes were assessed by way of recording twopoint discrimination, protective sensation, ulcer formation, and the rate of return to normal footwear.

\section{Results}

Patients were followed up postoperatively for a mean of 24 months (range: 8-48 months). All of the flaps survived with the exception of two cases in which partial skin flap necrosis secondary to infection was encountered. One required debridement and skin grafting, whereas the other was successfully managed conservatively. Both patients were diabetic and healed without secondary complications. Two flaps required reexploration secondary to venous congestion and both were successfully salvaged. The size of the flaps ranged from 10 to $32 \mathrm{~cm}$ in length to 6 to $9 \mathrm{~cm}$ in width, with a mean surface area of $180 \mathrm{~cm}^{2}$. Sensory nerve coaptation of the LFCN to an available sensory nerve at the recipient site was performed in 12 cases. Four patients with small calcaneal defects were treated with antibiotic beads to fill the dead space and control the infection, and one patient with total destruction of the calcaneus secondary to osteomyelitis underwent second-stage calcaneal reconstruction with a double-barrelled free fibula osteocutaneous flap. All donor sites were closed directly with no episodes of postoperative dehiscence. In five cases involving large soft tissue defects, this was achieved by way of splitting the skin paddle as described earlier. In those patients with no bony involvement, the average time of returning to work with unaided mobility was 7.5 weeks. Four of the five cases with associated calcaneal osteomyelitis achieved this at 9 to 10 weeks, wher as one patient who underwent total calcaneal reconstruction obtained full unaided weight-bearing status at 32 weeks postoperatively. During the follow-up period, the neurotized flaps demonstrated a static two-point discrimination between 12 and $15 \mathrm{~mm}$ at 5 months postprocedure. 
564 ALT Flap for Large Defects of the Weight-Bearing Foot Pappalardo et al.

\begin{tabular}{|c|c|c|c|c|c|c|c|c|c|c|c|c|c|c|c|c|}
\hline 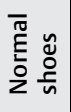 & 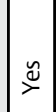 & $\stackrel{\check{x}}{\succ}$ & $\stackrel{\check{\nu}}{\varnothing}$ & $\stackrel{\check{x}}{\succ}$ & $\stackrel{\check{\Psi}}{\rightleftharpoons}$ & $\stackrel{\check{\nu}}{\rightleftharpoons}$ & $\stackrel{\check{\Xi}}{\rightleftharpoons}$ & $\stackrel{\check{x}}{\succ}$ & $\stackrel{\check{u}}{\rightleftharpoons}$ & $\stackrel{\check{y}}{\rightleftharpoons}$ & 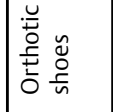 & $\stackrel{\check{y}}{\rightleftharpoons}$ & 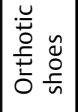 & $\stackrel{\check{\varpi}}{\rightleftharpoons}$ & $\stackrel{๊}{\succ}$ & $\stackrel{\check{y}}{\rightleftharpoons}$ \\
\hline 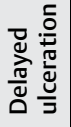 & 일 & 2 & $\frac{0}{2}$ & 2 & 2 & $2 \frac{0}{2}$ & 2 & 2 & 2 & $2 \frac{0}{2}$ & 2 & 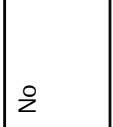 & 2 & 2 & $\frac{0}{2}$ & 2 \\
\hline 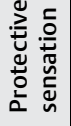 & $\stackrel{\check{c}}{\searrow}$ & $\stackrel{\check{y}}{\rightleftharpoons}$ & $\stackrel{\check{\nu}}{\rightleftharpoons}$ & $\stackrel{\check{\varphi}}{\rightleftharpoons}$ & $\stackrel{\check{g}}{\succ}$ & $\stackrel{\check{\nu}}{\rightleftharpoons}$ & $\stackrel{\check{\Perp}}{\rightleftharpoons}$ & $\stackrel{\check{\nu}}{\rightleftharpoons}$ & $\stackrel{\check{\nu}}{\rightleftharpoons}$ & $\stackrel{\check{\nu}}{\rightleftharpoons}$ & 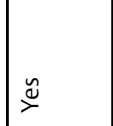 & $\stackrel{\check{\nu}}{\rightleftharpoons}$ & $\stackrel{\check{y}}{\nearrow}$ & $\stackrel{\check{\varpi}}{\rightleftharpoons}$ & $\stackrel{\check{\nu}}{\succ}$ & 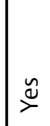 \\
\hline 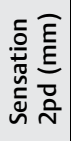 & $\frac{s}{z}$ & $\stackrel{n}{\sim}$ & $\simeq$ & $\simeq$ & $\frac{\S}{z}$ & $\stackrel{\sim}{\sim}$ & $\simeq$ & $\frac{\Sigma}{z}$ & $\simeq$ & $\simeq$ & $\frac{\mathbb{z}}{z}$ & $\stackrel{\llcorner}{\llcorner}$ & $\frac{\kappa}{z}$ & $\simeq$ & $\stackrel{\Perp}{\llcorner}$ & $\frac{\pi}{z}$ \\
\hline 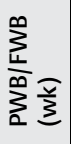 & $\frac{\circ}{7}$ & $\frac{\infty}{\sigma}$ & $\frac{\alpha}{z}$ & $\frac{\omega}{m}$ & $\frac{\varrho}{\sigma}$ & $\frac{\infty}{\sigma}$ & $\frac{0}{\sigma}$ & $\stackrel{\circ}{\frac{9}{r}}$ & $\frac{9}{6}$ & $\frac{\infty}{\gamma}$ & $\frac{\infty}{\forall}$ & $\frac{a}{6}$ & $\frac{6}{\gamma}$ & $\frac{\sigma}{\sigma}$ & $\frac{\circ}{\infty}$ & $\frac{\infty}{\gamma}$ \\
\hline 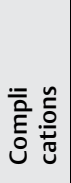 & 인 & z & z & i & 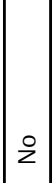 & 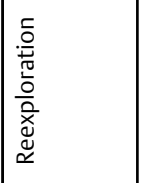 & z & 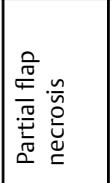 & z & z & z & i & i & z & $\ddot{2}$ & 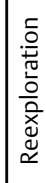 \\
\hline 근 $\overline{\bar{O}}$ & \& & $\mathscr{\gamma}$ & $\stackrel{ \pm}{\sim}$ & $\stackrel{\infty}{\sigma}$ & $\stackrel{\llcorner}{\llcorner}$ & $\stackrel{\text { ก }}{\circ}$ & 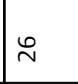 & $\stackrel{\text { N }}{2}$ & $\stackrel{\rho}{\circ}$ & $\infty$ & $\infty$ & $\circ$ & \pm & $\stackrel{\Xi}{\sim}$ & $\stackrel{9}{-}$ & 9 \\
\hline 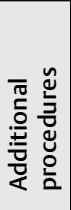 & 2 & 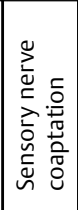 & 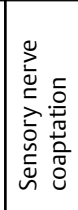 & 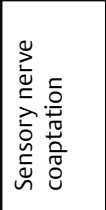 & $\stackrel{0}{2}$ & 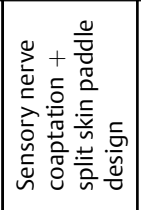 & 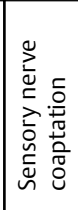 & 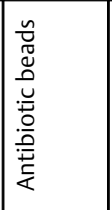 & 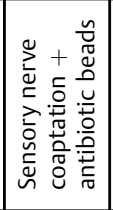 & 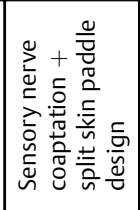 & $\stackrel{0}{2}$ & 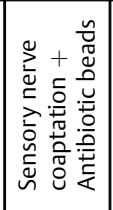 & i & 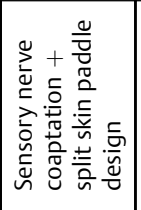 & 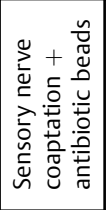 & 울 \\
\hline$\stackrel{0}{2}$ & $=$ & $=$ & $=$ & $=$ & $=$ & $=$ & $=$ & $\equiv$ & $\equiv$ & $=$ & $=$ & $\equiv$ & $=$ & $=$ & $\equiv$ & $=$ \\
\hline 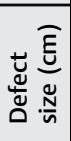 & $\begin{array}{l}\circ \\
\times \\
\infty \\
\infty\end{array}$ & $\begin{array}{l}a \\
x \\
\approx\end{array}$ & 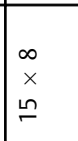 & $\mid \begin{array}{l}0 \\
\times \\
\circ \\
\end{array}$ & $\begin{array}{l}\circ \\
\times \\
\circ \\
\end{array}$ & $\mid \begin{array}{l}0 \\
\times \\
\infty \\
\square\end{array}$ & $\begin{array}{l}\infty \\
\times \\
\stackrel{2}{N}\end{array}$ & $\begin{array}{l}a \\
x \\
g \\
\end{array}$ & $\begin{array}{l}\infty \\
\times \\
\approx \\
\tilde{N}\end{array}$ & $\begin{array}{l} \pm \\
x \\
\propto \\
\simeq\end{array}$ & $\begin{array}{l}\infty \\
\times \\
\times \\
\infty\end{array}$ & $\begin{array}{l} \pm \\
\dot{x} \\
\sigma\end{array}$ & $\begin{array}{l}\stackrel{n}{x} \\
\times \\
\sigma\end{array}$ & $\begin{array}{l}0 \\
x \\
x \\
\square\end{array}$ & $\begin{array}{l}a \\
\times \\
\stackrel{\omega}{N}\end{array}$ & $\begin{array}{l}a \\
\times \\
\stackrel{2}{2}\end{array}$ \\
\hline 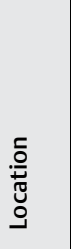 & 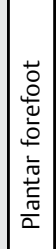 & 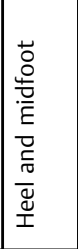 & 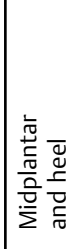 & \begin{tabular}{|l}
$\bar{\Xi}$ \\
Ф்
\end{tabular} & 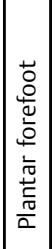 & 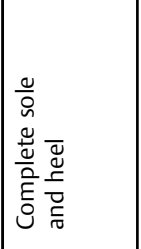 & 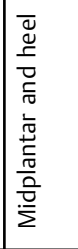 & 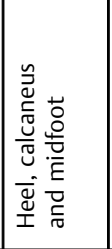 & 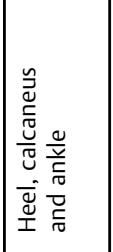 & 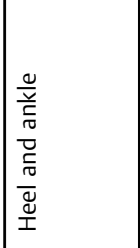 & 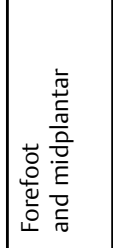 & 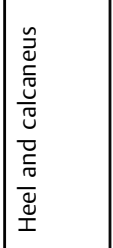 & 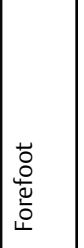 & 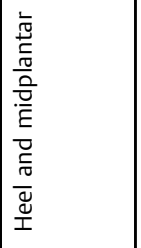 & 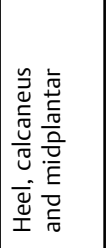 & 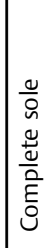 \\
\hline ठेे & 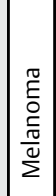 & 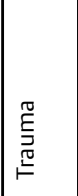 & 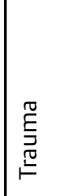 & 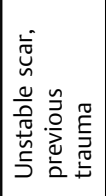 & 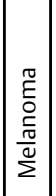 & 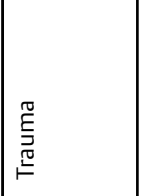 & 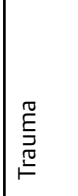 & 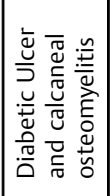 & 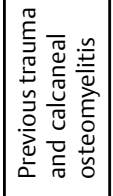 & 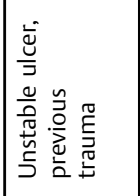 & 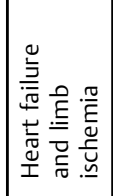 & 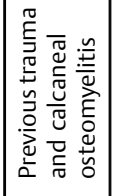 & 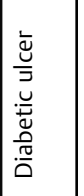 & 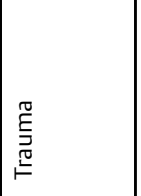 & 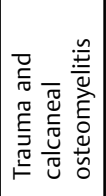 & 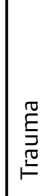 \\
\hline 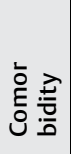 & $\Sigma$ & 芒 & io & 2 & 2 & 2 & 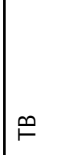 & $\mid \begin{array}{l}z \\
\text { 至 } \\
\sum_{0}\end{array}$ & ¿ & 2 & 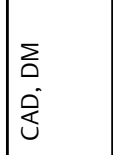 & 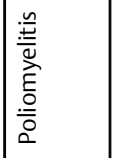 & \begin{tabular}{|l}
$z$ \\
至 \\
$\sum_{0}$
\end{tabular} & 亲 & 莹 & 楃 \\
\hline$\stackrel{\times}{\varpi}$ & $\Sigma$ & $\Sigma$ & \llcorner & $\Sigma$ & $\Sigma$ & \llcorner & \llcorner & \llcorner & $\Sigma$ & \llcorner & $\Sigma$ & $\Sigma$ & $\Sigma$ & 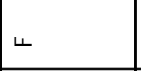 & $\Sigma$ & $\Sigma$ \\
\hline छัष & 8 & ถి & $\stackrel{\sim}{\sim}$ & $\bar{N}$ & 8 & 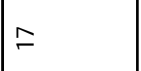 & in & in & กิ & $\tilde{m}$ & 6 & $\tilde{m}$ & in & in & F & 8 \\
\hline 苞 & - & $\sim$ & $m$ & $\nabla$ & in & 0 & $\wedge$ & $\infty$ & a & $\circ$ & $=$ & $\simeq$ & $\stackrel{m}{r}$ & $\Xi$ & $\stackrel{\Perp}{\llcorner}$ & $\stackrel{\bullet}{\leftarrow}$ \\
\hline
\end{tabular}




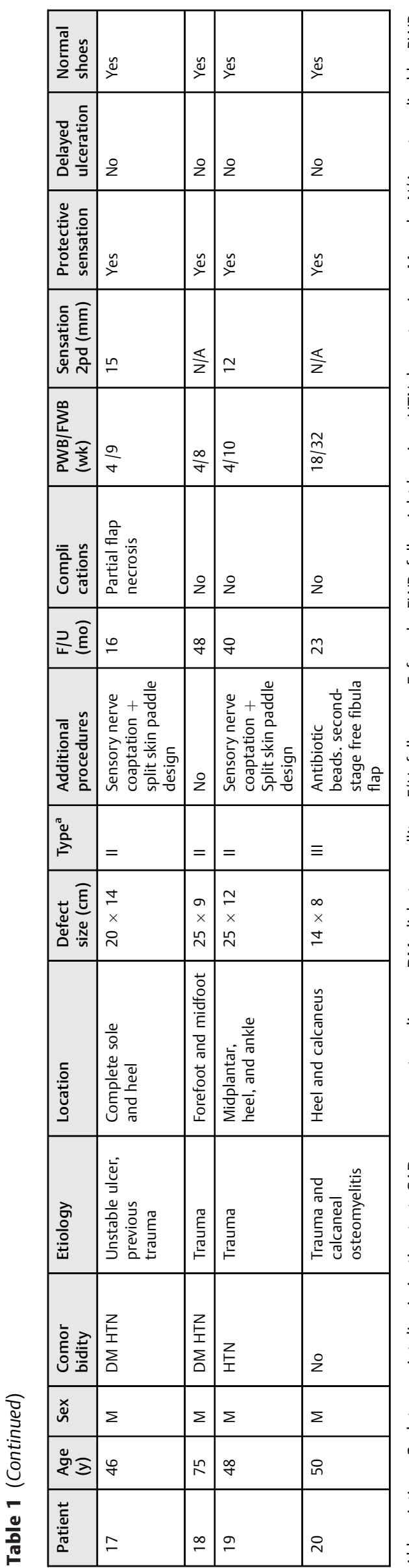

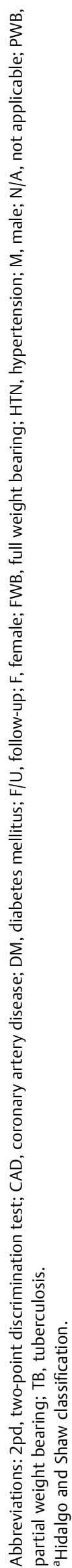

On the other hand, two-point discrimination in non-neurotized flaps was never detectable. Protective sensation returned in all patients and was observed as early as 4 months in nine patients from the neurotized flap group. Eighteen patients were able to wear normal shoes, whereas two patients required adjunctive orthotic footwear. Over the entire follow-up period, no episodes of postoperative ulceration over the reconstructed weight-bearing zones were encountered and all the patients were satisfied regarding the functional and aesthetic results achieved (-Figs. 1-3).

\section{Video 1}

A 50-year-old man underwent two-stage total calcaneal reconstruction with free ALT flap and free fibula osteocutaneous flap. The video demonstrates the patient walking with normal gait. Online content including video sequences viewable at: https://www. thieme-connect.com/products/ejournals/html/doi/ 10-1055-s-0036-1584204-JRM-15-0304-v1_1.mp4.

\section{Discussion}

The primary goals in the reconstruction of the weight-bearing zones of the foot are to restore function and allow the patient to return to wearing normal footwear while keeping donorsite morbidity to a minimum. ${ }^{15,20,21}$ However, this is a challenging task, as the unique weight-bearing property of the foot is almost impossible to replace. The reconstructive principle of replacing "like with like" is achievable only for small- to medium-sized soft-tissue defects with pedicled ${ }^{3-5}$ or free flaps taken from the instep. ${ }^{22,23}$ These flaps include the same anatomical features that are unique to the plantar skin, namely the thick, waxy glabrous skin, a thin layer of subcutaneous fat, and dense fibrous septae that anchor the skin to the underlying fascia. ${ }^{5}$ However, when defects of the plantar foot are larger than $100 \mathrm{~cm}^{2}$ or are associated with fractures or chronic infection, skin-grafted muscle flaps and free fasciocutaneous flaps are considered the two main reconstructive options. ${ }^{8-14}$ Historically skin-grafted free muscle flaps were believed to yield optimal results ${ }^{8,11,12}$; however, functional impairment, absence of sensation and high ulceration rates have since been highlighted. ${ }^{13,14}$ On the other hand, fasciocutaneous flap can provide thin, pliable tissue that can be neurotized, but the main disadvantage is the high modulus of shear in the subcutaneous plane resulting in a degree of instability when mobilizing. ${ }^{10,13,24}$

Perforator skin flaps and especially the ALT flap have been used in the reconstruction of a wide variety of soft tissue defects with good functional and aesthetic results, ${ }^{15,25}$ and many variations and modifications have been described for its use. ${ }^{18}$ Indeed, in the setting of foot and ankle reconstruction, the ALT flap is gaining in popularity (-Table 2). The main advantage of the ALT about the reconstruction of large defects of the weight-bearing foot is its versatility in design. It can be raised as a double-paddled flap to allow for a bespoke threedimensional reconstruction, harvested as a thin skin flap or 

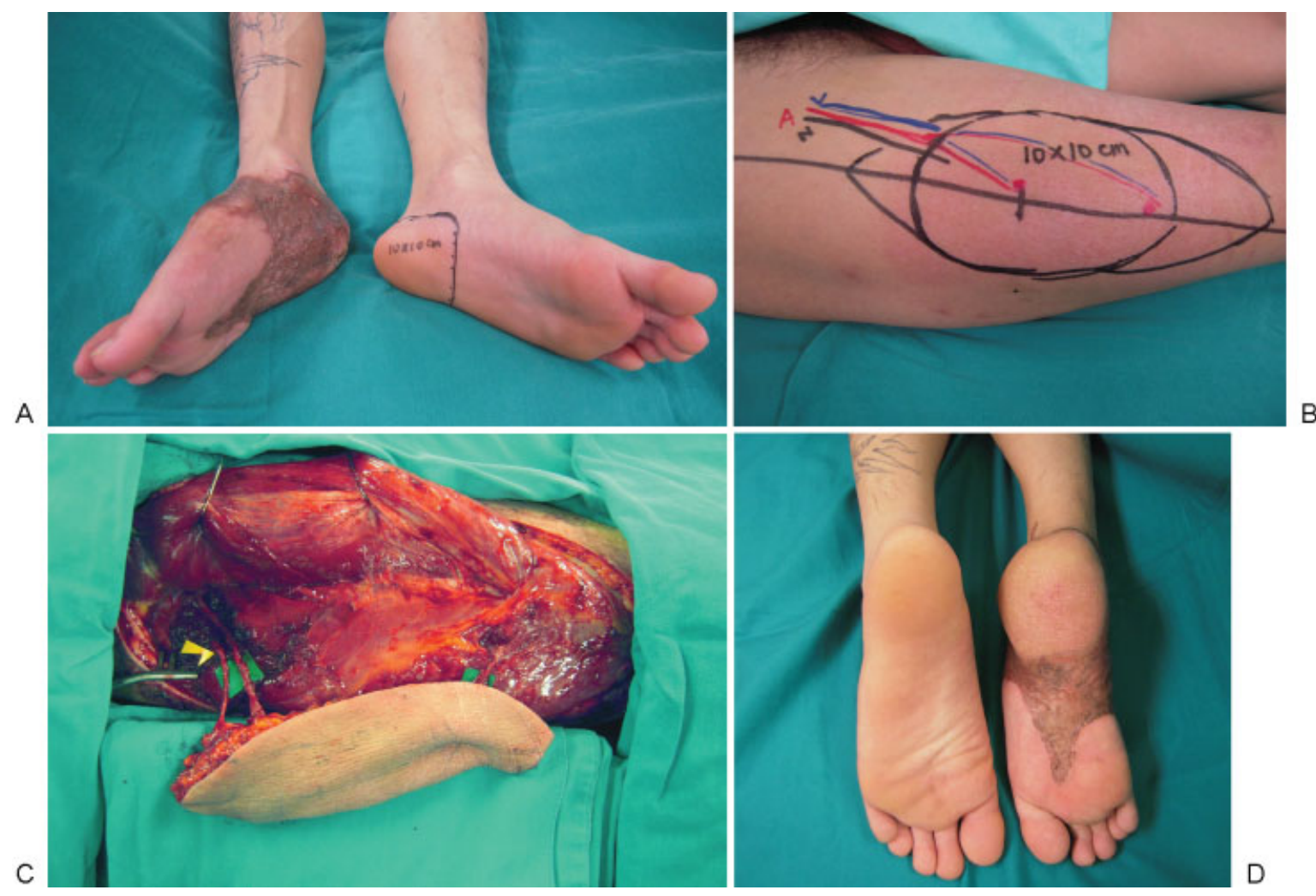

Fig. 1 (A) Case 4. A 21-year-old man presented with an unstable scar after split-thickness skin grafting over the right heel that was preventing ambulation. (B, C) Postdebridement, a 10- $\times 10-\mathrm{cm}$ ALT perforator flap was harvested with the LFCN (yellow arrowhead). The artery was anastomosed in an end-to-side fashion to the posterior tibial artery and the LFCN was coapted to a branch of the medial plantar nerve. (D) At -2year follow-up, the two-point discrimination in the flap was $12 \mathrm{~mm}$. The reconstructed heel regained protective sensation, no tissue breakdown has been observed, and the patient is able to ambulate well with normal shoes. Source: Fig. 1B and C Reprinted with permission from Taylor and Francis Group LLC Books. Levine JP, Wei FC, Reconstructive Surgery of the Lower Extremity. Vol. 1. St. Louis, MO: Quality Medical Publishing; 2013:565.

raised as a myocutaneous flap with a segment of vastus lateralis to obliterate dead space, as has been reported in previous studies. ${ }^{15}$ Hong and Kim have also noted that the flap can be thinned down to a thickness of 3 to $6 \mathrm{~mm}$ to reduce the need for secondary debulking procedures and improve stability. ${ }^{15}$ Although we agree that this is a good solution for the non-weight-bearing zones of the foot as it can provide excellent contour, we feel that for the heel a wellcushioned reconstruction is essential to prevent breakdown over the underlying calcaneus and allow the patient to ambulate barefoot without special shoes. Furthermore, Hollenbeck et al noted that, regarding the weight-bearing subunits of the foot, thin flaps may indeed be at increased risk of breakdown. ${ }^{20}$

The question of whether or not to raise a neurotized flap and perform sensory nerve coaptation at the recipient is another area of debate. Indeed, a normal range for two-point discrimination in the foot has not been precisely determined; however, the study by Nolan showed that the skin covering the plantar surface of the great toe demonstrated the greatest sensitivity in two-point discrimination ability with a mean value of $6.6 \mathrm{~mm} .{ }^{47}$ In addition, in a more recent study by Trevatt et al, it was shown that the mean two-point discrimination in native tissue of the foot and ankle region was $29 \mathrm{~mm}$ (standard deviation [SD] 11.9). ${ }^{48}$ This suggests that a range exists for normal two-point discrimination in the foot of between 6.6 and $29 \mathrm{~mm}$. Some studies have indeed revealed that patients reconstructed with sensate flaps regained earlier sensibility and faster rehabilitation and return to work. ${ }^{15,26,27}$ However, most authors have highlighted no significant difference between neurotized and non-neurotized flaps regarding sensory recovery and long-term ulceration rate. ${ }^{11,15,27,28}$ Indeed, in our series we have shown that return to protective sensation was achieved in all cases despite 8/20 flaps being non-neurotized. However, as highlighted in previous studies, ${ }^{15,27}$ a faster return to protective sensation can be expected with neurotized flaps and in our series this was seen as early as 4 months postoperatively. At our institution, we adopt a policy of performing neurotization when sensory nerve is available at the recipient site. We feel that in young patients with trauma, this is worthwhile as it may speed up sensory recovery and functional return; however, further investigation is warranted to establish the exact effect that this may have on functional outcome. When raising an ALT perforator flap with the lateral cutaneous nerve of the thigh, the additional time for dissection is minimal as the nerve is easily identifiable in the subcutaneous tissue of the proximal skin paddle. However, care must be taken to orient the skin paddle such that the coaptation of the nerve does not put undue tension on the 

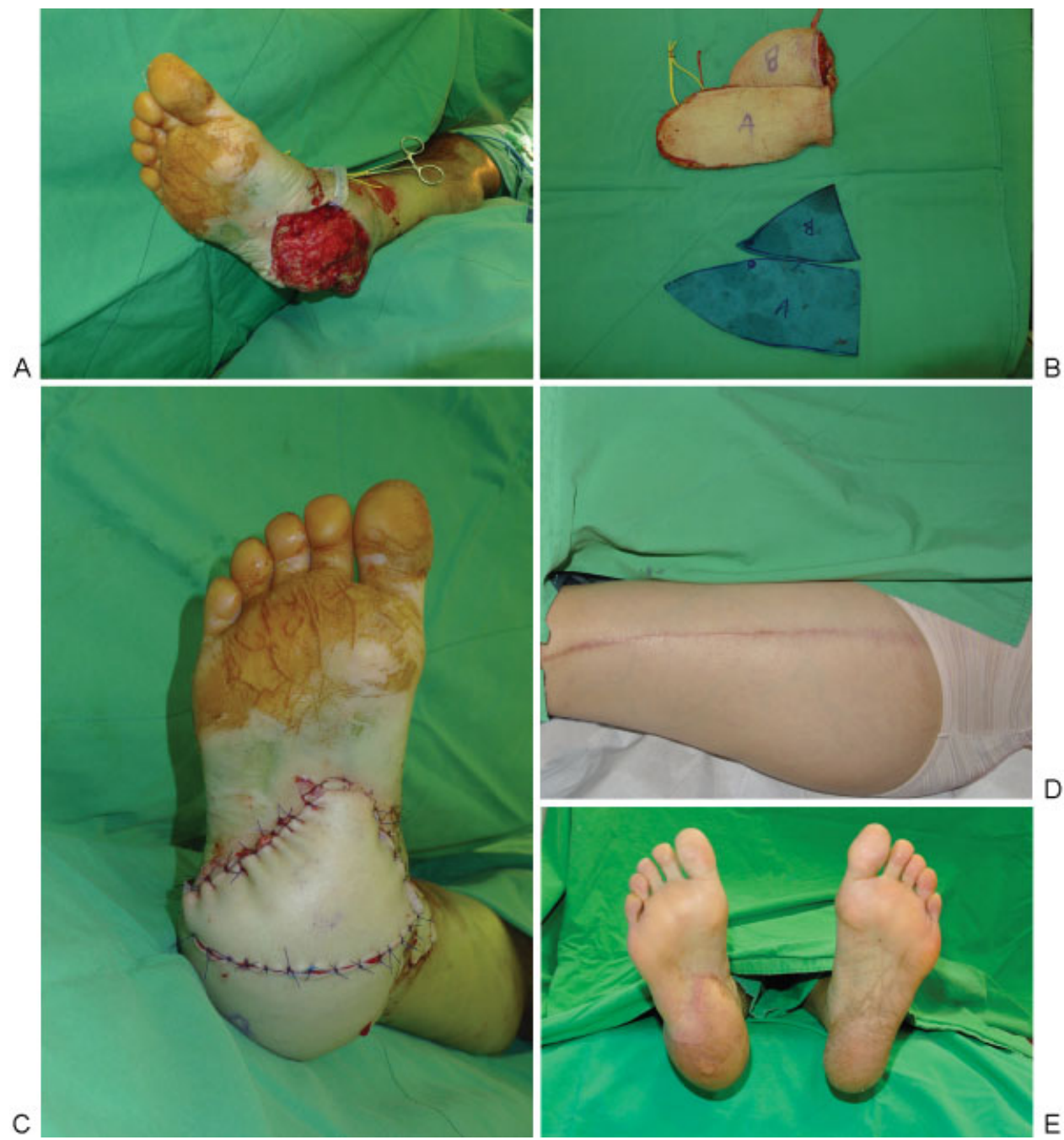

Fig. 2 (A) Case 14. A 54-year-old woman presented with right heel pad degloving injury. After debridement, the defect size measured $14 \times 16 \mathrm{~cm}$ and was divided into subunits A,B for a bespoke three-dimensional subunit reconstruction. (B, C) A $23-\times 8-\mathrm{cm}$ split neurotized free ALT based on two perforators was harvested. The neurotized A flap was used to reconstruct the weight-bearing heel pad, while the B flap was rotated to reconstruct the area just distal to the heel. (D) Primary closure of the donor site. (E) At 2-year follow-up, the foot demonstrated good contour, a 12-mm two-point discrimination, and recovery of protective sensation.

vascular anastomosis. The coaptation of the nerve to a sensory nerve in the foot is relatively quick and does not itself add much time to the procedure; however, meticulous reverse planning is essential to ensure that adequate nerve length has been harvested and that the skin paddle is of correct the dimensions to allow for tension-free neurotization. It is this planning process that indeed adds some time to the procedure, and the total additional operative time for neurotized versus non-neurotized flaps was on average 1 hour in our study.

Traditionally, when there has been no need for bony reconstruction, the use of free muscle flaps has been considered the treatment of choice. ${ }^{8,29,30}$ They provide robust vascular cover and great contour; however, skin grafting is required, which can result in long-term problems regarding breakdown over the graft. In our experience, muscle flaps with skin grafts for reconstruction of weight-bearing subunits of the foot are inferior to thin fasciocutaneous free flaps. We feel that not only is the donor-site morbidity less with a fasciocutaneous perforator flap, but the skin cover at the recipient site is more robust and less likely to ulcerate in the long term. Indeed, a recent systematic review by Fox et al demonstrated that there was a higher rate of ulceration, revision, and the need for specialized foot wear in patients undergoing reconstruction with muscle flaps as compared with fasciocutaneous flaps. ${ }^{10}$

Although the study included more than 160 patients undergoing plantar resurfacing, these differences were not statistically significant demonstrating the need for more reconstructive surgeons to collaborate on multi-institutional prospective studies with robust outcome measures. In addition, the use of ALT flaps in the treatment of osteomyelitis is now well-established, as they provide a large amount of wellvascularized tissue that can be used to obliterate dead space and promote infection-free union. ${ }^{31}$ Indeed, numerous articles have reported on the excellent outcomes achieved with fasciocutaneous and skin flaps in this setting. ${ }^{24,32}$ Moreover, fasciocutaneous flaps can be easily lifted in 


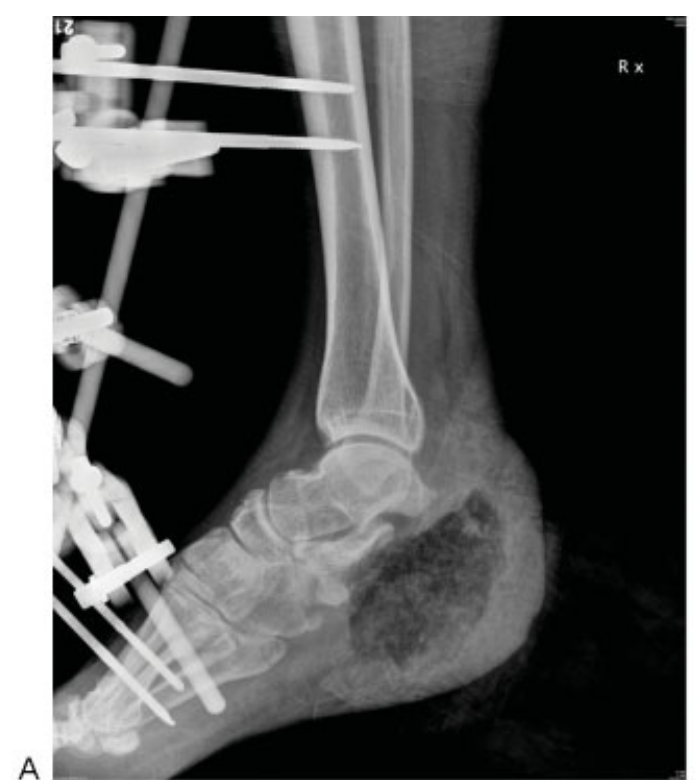

A

C
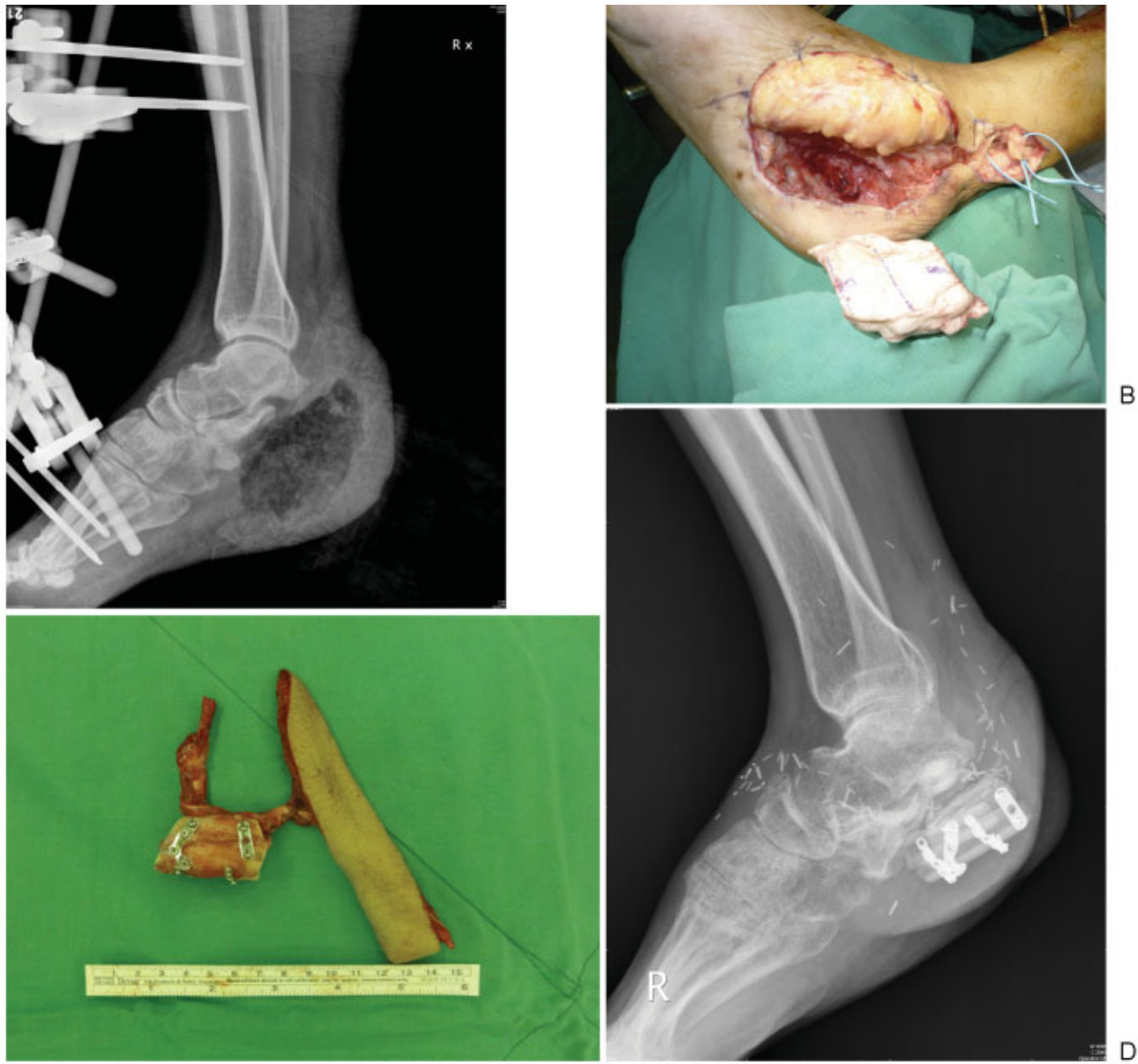

\section{B}

E

Fig. 3 (A) Case 20. A 50-year-old man presented with an open wound over the medial aspect of the right heel and open calcaneal fracture secondary to a fall from height. X-ray revealed an extensive calcaneal defect due to osteomyelitis. After serial debridement, the skin defect measured $14 \times 8 \mathrm{~cm}$ with total calcaneal loss. A 12- $\times$ 6-cm ALT flap was elevated for first-stage soft tissue coverage, and antibiotic beads were deployed to fill the bony defect. (B) The second-stage reconstruction was performed 45 days later. The calcaneal defect was preshaped with bone cement as a three-dimensional template. (C) Double-barrelled fibula osteocutaneous flap with a third barrel of free bone graft was modeled to match the size and shape of the template and inserted in situ using Kirschner wires for complete calcaneal reconstruction. (D, E) At 32 weeks, postoperative X-ray showed bony union and full-weight bearing was regained. (See - Video 1 , which demonstrates the patient walking with normal gait.) 
Table 2 Previous studies detailing the use of free ALT flaps in the reconstruction of defects of the foot and ankle

\begin{tabular}{|l|l|l|l|l|l|}
\hline Reference & Country & Source & $\begin{array}{l}\text { No. of } \\
\text { patients }\end{array}$ & $\begin{array}{l}\text { Type of } \\
\text { flap }\end{array}$ & $\begin{array}{l}\text { Site of } \\
\text { defect }\end{array}$ \\
\hline Pappalardo et al. 2016 & Taiwan & Present study & 20 & ALT & Plantar resurfacing \\
\hline Acar et al. $2015^{41}$ & Turkey & J Reconstr Microsurg & 11 & ALT & Foot and ankle \\
\hline Hu et al. $2015^{42}$ & China & Injury & 25 & ALT & Foot and ankle \\
\hline El-Gammal et al. $2013^{43}$ & Egypt & Microsurgery & 42 & ALT & Dorsal foot \\
\hline Liu et al. $2013^{44}$ & China & PLoS One & 24 & ALT & Dorsal foot, ankle, and plantar resurfacing \\
\hline Demirtas et al. $2010^{45}$ & Turkey & Foot Ankle Int & 5 & ALT & Dorsal foot \\
\hline Demirtas et al. $2010^{46}$ & Turkey & Foot Ankle Int & 16 & ALT & Dorsal foot, ankle, and plantar resurfacing \\
\hline Hong and Kim $2007^{15}$ & S. Korea & Plast Reconstr Surg & 69 & ALT & Plantar resurfacing \\
\hline
\end{tabular}

Abbreviation: ALT, anterolateral thigh flap.

second-stage procedures in which the bone needs to be accessed, and this represents another advantage in this approach over the skin-grafted muscle flap alternative.

In our series, we achieved good functional outcomes in all cases using free ALT fasciocutaneous flaps. We feel that an expert, thorough debridement of both the soft tissues and any affected bone, is paramount when tackling these challenging cases and is, in essence, the key step. Indeed, in 5 of 20 patients with associated calcaneal osteomyelitis, we achieved not only successful soft tissue coverage but also infection-free status of the bone. Use of antibiotic impregnated beads, a staged approach, meticulous debridement, and obliteration of all dead space with well-vascularized soft tissue were, we feel, key in achieving these results. Moreover, despite amputation as historically being the treatment of choice for complex (type III) calcaneal defects, ${ }^{33,34}$ we were able to not only salvage but also achieve a return to full weight-bearing status in a patient with total calcaneal loss secondary to infection.

In this modern era of reconstructive surgery, we should strive to improve outcomes not only at the recipient site but also at the donor site. ${ }^{35-37}$ In a study previously performed at our institution, we demonstrated that it was possible to directly close the ALT donor-site defects that were less than $16 \%$ of the thigh circumference. ${ }^{19}$ With this in mind, in five patients for whom a wide skin paddle was required, we adopted the principle of designing the ALT flap based on two sizable perforators. The skin paddle could then be split to achieve a bespoke three-dimensional reconstruction at the recipient site while allowing for direct closure of the donor site. Indeed, this technique is well established when attempting to reconstruct irregularly shaped defects. ${ }^{38-40}$ The need to raise the flap on at least two sizable perforators requires the need for accurate perforator mapping, however, and we tend to achieve this simply by using handheld Doppler, although the use of computed tomography (CT) angiography or color duplex ultrasound could represent alternative strategies to this end.

Although previous studies have reported on the use of the ALT in foot and ankle reconstruction (-Table 2), we feel that our series differs from that of previous studies for several reasons. First, our series deals with reconstructing large defects of the foot with the mean size of the ALT flaps that we used being $180 \mathrm{~cm}^{2}$. Moreover, we used several additional techniques to supplement our reconstructions, including the harvest of the LFCN for neurotization, splitting of the skin paddle based on at least two sizable perforators to ensure direct donor-site closure, and a three-dimensional bespoke inset at the recipient site. Indeed, in a single case we succeeded in achieving a functional reconstruction of total calcaneal loss with the use of an ALT flap and a doublebarrelled free fibula osteocutaneous flap.

\section{Conclusion}

The ALT flap represents a versatile reconstructive option when tackling defects of the weight-bearing zones of the foot. It can be raised with a sensory nerve for coaptation at the recipient site and split into two paddles to achieve a bespoke three-dimensional inset. The skin is robust and the soft tissue is well vascularized that can help when associated calcaneal osteomyelitis is present. In our series protective sensation returned in all cases, no tissue breakdown has yet been detected throughout the follow-up period, and all patients returned to full weight-bearing status.

\section{Disclosure}

The authors have no financial interest to declare in relation to the content of this article.

\section{References}

1 Cai J, Cao X, Liang J, Sun B. Heel reconstruction. Plast Reconstr Surg 1997;99(2):448-453

2 Hidalgo DA, Shaw WW. Reconstruction of foot injuries. Clin Plast Surg 1986;13(4):663-680

3 Shaw WW, Hidalgo DA. Anatomic basis of plantar flap design: clinical applications. Plast Reconstr Surg 1986;78(5):637-649

4 Roblin P, Healy CM. Heel reconstruction with a medial plantar V-Y flap. Plast Reconstr Surg 2007;119(3):927-932

5 Oh SJ, Moon M, Cha J, Koh SH, Chung CH. Weight-bearing plantar reconstruction using versatile medial plantar sensate flap. J Plast Reconstr Aesthet Surg 2011;64(2):248-254

6 Jeng SF, Wei FC. Distally based sural island flap for foot and ankle reconstruction. Plast Reconstr Surg 1997;99(3):744-750 
7 Benito-Ruiz J, Yoon T, Guisantes-Pintos E, Monner J, Serra-Renom JM. Reconstruction of soft-tissue defects of the heel with local fasciocutaneous flaps. Ann Plast Surg 2004;52(4):380-384

8 May JW Jr, Rohrich RJ. Foot reconstruction using free microvascular muscle flaps with skin grafts. Clin Plast Surg 1986;13(4):681-689

9 Lu S, Chai Y, Wang C, Wen G. Complex heel reconstruction with a sural fasciomyocutaneous perforator flap. J Reconstr Microsurg 2014;30(2):83-90

10 Fox CM, Beem HM, Wiper J, Rozen WM, Wagels M, Leong JC. Muscle versus fasciocutaneous free flaps in heel reconstruction: systematic review and meta-analysis. J Reconstr Microsurg 2015; 31(1):59-66

11 May JW Jr, Halls MJ, Simon SR. Free microvascular muscle flaps with skin graft reconstruction of extensive defects of the foot: a clinical and gait analysis study. Plast Reconstr Surg 1985;75(5): 627-641

12 Sommerlad BC, McGrouther DA. Resurfacing the sole: long-term follow-up and comparison of techniques. Br J Plast Surg 1978; 31(2):107-116

13 Sönmez A, Bayramiçli M, Sönmez B, Numanoğlu A. Reconstruction of the weight-bearing surface of the foot with nonneurosensory free flaps. Plast Reconstr Surg 2003;111(7):2230-2236

14 Ohjimi H, Taniguchi Y, Kawano K, Kinoshita K, Manabe T. A comparison of thinning and conventional free-flap transfers to the lower extremity. Plast Reconstr Surg 2000;105(2):558-566

15 Hong JP, Kim EK. Sole reconstruction using anterolateral thigh perforator free flaps. Plast Reconstr Surg 2007;119(1):186-193

16 Song YG, Chen GZ, Song YL. The free thigh flap: a new free flap concept based on the septocutaneous artery. Br J Plast Surg 1984; 37(2):149-159

17 Kuo YR, Seng-Feng J, Kuo FM, Liu YT, Lai PW. Versatility of the free anterolateral thigh flap for reconstruction of soft-tissue defects: review of 140 cases. Ann Plast Surg 2002;48(2):161-166

18 Wei FC, Jain V, Celik N, Chen HC, Chuang DC, Lin CH. Have we found an ideal soft-tissue flap? An experience with 672 anterolateral thigh flaps. Plast Reconstr Surg 2002;109(7):2219-2226, discussion 2227-2230

19 Boca R, Kuo YR, Hsieh CH, Huang EY, Jeng SF. A reliable parameter for primary closure of the free anterolateral thigh flap donor site. Plast Reconstr Surg 2010;126(5):1558-1562

20 Hollenbeck ST, Woo S, Komatsu I, Erdmann D, Zenn MR, Levin LS Longitudinal outcomes and application of the subunit principle to 165 foot and ankle free tissue transfers. Plast Reconstr Surg 2010; 125(3):924-934

21 Lin $\mathrm{CH}$, Lin $\mathrm{CH}$. Reconstruction of the weight-bearing heel. In: Pu LLQ Levine JP, Wei FC, eds. Reconstructive Surgery of the Lower Extremity. Vol.1. St. Louis, MO: Quality Medical Publishing; 2013: 1251-1267

22 Morrison WA, Crabb DM, O'Brien BM, Jenkins A. The instep of the foot as a fasciocutaneous island and as a free flap for heel defects. Plast Reconstr Surg 1983;72(1):56-65

23 Scheufler O, Kalbermatten D, Pierer G. Instep free flap for plantar soft tissue reconstruction: indications and options. Microsurgery 2007;27(3):174-180

24 Weinzweig N, Davies BW. Foot and ankle reconstruction using the radial forearm flap: a review of 25 cases. Plast Reconstr Surg 1998; 102(6):1999-2005

25 Hong JP. Reconstruction of the diabetic foot using the anterolateral thigh perforator flap. Plast Reconstr Surg 2006;117(5):1599-1608

26 Kuran I, Turgut G, Bas L, Ozkan T, Bayri O, Gulgonen A. Comparison between sensitive and nonsensitive free flaps in reconstruction of the heel and plantar area. Plast Reconstr Surg 2000;105(2): 574-580

27 Santanelli F, Tenna S, Pace A, Scuderi N. Free flap reconstruction of the sole of the foot with or without sensory nerve coaptation. Plast Reconstr Surg 2002;109(7):2314-2322, discussion 2323-2324
28 Potparić Z, Rajacić N. Long-term results of weight-bearing foot reconstruction with non-innervated and reinnervated free flaps. Br J Plast Surg 1997;50(3):176-181

29 Mathes SJ, Alpert BS, Chang N. Use of the muscle flap in chronic osteomyelitis: experimental and clinical correlation. Plast Reconstr Surg 1982;69(5):815-829

30 Gosain A, Chang N, Mathes S, Hunt TK, Vasconez L. A study of the relationship between blood flow and bacterial inoculation in musculocutaneous and fasciocutaneous flaps. Plast Reconstr Surg 1990;86(6):1152-1162, discussion 1163

31 Hong JP, Shin HW, Kim JJ, Wei FC, Chung YK. The use of anterolateral thigh perforator flaps in chronic osteomyelitis of the lower extremity. Plast Reconstr Surg 2005;115(1):142-147

32 Musharafieh R, Osmani O, Musharafieh U, Saghieh S, Atiyeh B. Efficacy of microsurgical free-tissue transfer in chronic osteomyelitis of the leg and foot: review of 22 cases. J Reconstr Microsurg 1999;15(4):239-244

33 Baumhauer JF, Fraga CJ, Gould JS, Johnson JE. Total calcanectomy for the treatment of chronic calcaneal osteomyelitis. Foot Ankle Int 1998;19(12):849-855

34 Barbour J, Saunders S, Hartsock L, Schimpf D, O'Neill P. Calcaneal reconstruction with free fibular osteocutaneous flap. J Reconstr Microsurg 2011;27(6):343-348

35 Jeng SF, Tan NC. Optimizing aesthetic and functional outcomes at donor sites. Chang Gung Med J 2012;35(3):219-230

36 Kimata Y, Uchiyama K, Ebihara S, et al. Anterolateral thigh flap donor-site complications and morbidity. Plast Reconstr Surg 2000; 106(3):584-589

37 Calderón W, Borel C, Roco H, Piñeros JL, Olguin F. Primary closure of donor site in anterolateral cutaneous thigh free flap. Plast Reconstr Surg 2006;117(7):2528-2529

38 Tsai FC, Yang JY, Mardini S, Chuang SS, Wei FC. Free split-cutaneous perforator flaps procured using a three-dimensional harvest technique for the reconstruction of postburn contracture defects. Plast Reconstr Surg 2004;113(1):185-193, discussion 194-195

39 Marsh DJ, Chana JS. Reconstruction of very large defects: a novel application of the double skin paddle anterolateral thigh flap design provides for primary donor-site closure. J Plast Reconstr Aesthet Surg 2010;63(1):120-125

40 Chang NJ, Waughlock N, Kao D, Lin CH, Lin CH, Hsu CC. Efficient design of split anterolateral thigh flap in extremity reconstruction. Plast Reconstr Surg 2011;128(6):1242-1249

41 Acar MA, Güleç A, Aydin BK, Erkoçak ÖF, Yilmaz G, Şenaran H. Reconstruction of foot and ankle defects with a free anterolateral thigh flap in pediatric patients. J Reconstr Microsurg 2015;31(3): 225-232

$42 \mathrm{Hu}$ R, Ren YJ, Yan L, et al. A free anterolateral thigh flap and iliotibial band for reconstruction of soft tissue defects at children's feet and ankles. Injury 2015;46(10):2019-2023

43 El-Gammal TA, El-Sayed A, Kotb MM, et al. Dorsal foot resurfacing using free anterolateral thigh (ALT) flap in children. Microsurgery 2013;33(4):259-264

44 Liu L, Cao X, Zou L, Li Z, Cao X, Cai J. Extended anterolateral thigh flaps for reconstruction of extensive defects of the foot and ankle. PLoS ONE 2013;8(12):e83696

45 Demirtas Y, Neimetzade T, Kelahmetoglu O, Guneren E. Free anterolateral thigh flap for reconstruction of car tire injuries of children's feet. Foot Ankle Int 2010;31(1):47-52

46 Demirtas Y, Neimetzade T, Kelahmetoglu O, Guneren E. Comparison of free muscle and perforator skin flaps for soft tissue reconstruction of the foot and ankle. Foot Ankle Int 2010;31(1):53-58

47 Nolan MF. Limits of two-point discrimination ability in the lower limb in young adult men and women. Phys Ther 1983;63(9):1424-1428

48 Trevatt AE, Filobbos G, Ul Haq A, Khan U. Long-term sensation in the medial plantar flap: a two-centre study. Foot Ankle Surg 2014; 20(3):166-169 